\title{
ASPECTOS AGRONÔMICOS E PRODUTIVOS DOS HÍBRIDOS DE GIRASSOL (Helianthus annus L.) HELIO 251 E HELIO 360
}

\author{
Angelo Damian Pizzuti ${ }^{1}$, Ivan Luiz Brondani ${ }^{1}$, JoÃo Restle ${ }^{3}$ \\ 1 - Universidade Federal de Santa Maria - patmetz@hotmail.com \\ 2 - Professor Doutor do Instituto Federal Catarinense \\ 3 - Pesquisador Visitante/CNPq na Universidade Federal de Goiás
}

Guilherme Joner ${ }^{1}$, Patricia Alessandra Meneguzzi Metz ${ }^{1}$, Miguelangelo Ziegler Arboitte ${ }^{2}$, Luis

\section{RESUMO}

Objetivou-se com este estudo quantificar a produção e a participação de aquênios, folhas, colmo e capítulo, bem como a produção de matéria verde e seca de dois híbridos de girassol para produção de silagem. Foram utilizados dois híbridos de girassol: Helio 251 (H251) e Helio 360 (H360), implantados em resteva de aveia. A avaliação produtiva da cultura realizou-se pela contagem de 12 pontos de cinco metros lineares/ha de cada híbrido e a composição das plantas foi realizada com cinco amostras. $\mathrm{O}$ delineamento experimental foi inteiramente casualizado e as médias analisadas pelo teste Tukey. O H251 apresentou maior quantidade de plantas/m linear e por hectare $(3,99$ contra 3,12 plantas $/ \mathrm{m} ; 49.953,95$ contra
38.342,10 plantas/ha, respectivamente, para $\mathrm{H} 251 \mathrm{e}$ H360). Os capítulos do H360 foram mais pesados, quando expressos em matéria verde (MV) $(303,79$ g/planta) e seca (MS) (56,88 g/planta), consequentemente, apresentando maior peso de aquênio (151,09 e 100,12 g/planta, para MV e MS), quando comparado com o H251. O híbrido H360 apresentou maior peso de colmo, quando expresso em MV (120,95 contra 61,27 g/planta) e MS (48,58 contra 29,01 $\mathrm{g} /$ planta). Os maiores pesos de capítulo, aquênios e caule apresentados pelo H360 resultaram em plantas mais pesadas, além de superioridade na produção de MS/ha.

PALAVRAS-CHAVE: aquênio; capítulo; colmo; folha; matéria seca; matéria verde.

\section{AGRONOMIC AND PRODUCTIVE ASPECTS OF SUNFLOWER HYBRIDS (Helianthus annus L.) HELIO 251 AND HELIO 360}

This study had as objective to quantify achenes, leaves, stem and capitulum production and participation, as well as green and dry matter production of two sunflower hybrids for silage production. Two sunflower hybrids, Helio 251 (H251) and Helio 360 (H360), were used and implanted under oat stubble. The counting of twelve points with five linear meters/hectare of each hybrid was carried out to evaluate hybrid production and five samples were taken to evaluate plant composition. A complete randomized experimental design was used and the averages were analyzed by Tukey test. H251 hybrid presented higher plants per linear meter and per hectare (3.99 vs. 3.12 plants $/ \mathrm{m}$; $49,953.95$ vs. $38,342.10$ plants/ha, for $\mathrm{H} 251$ and H360, respectively). H360 capitulum were heavier 
than the ones from $\mathrm{H} 251$, when expressed in green (303.79 g/plant) or dry $(56.88 \mathrm{~g} / \mathrm{plant})$ matter basis, consequently, it showed heavier achenes (151.09 and $100.12 \mathrm{~g} /$ plant, respectively, for green and dry matter). H360 presented higher stem weight, when expressed in green (120.95 vs. $61.27 \mathrm{~g} /$ plant) or dry (48.58 vs. 29.01 $\mathrm{g} /$ plant) matter basis. The higher weights of capitulum, achene and stem presented by $\mathrm{H} 360$ resulted in heavier plants and superiority on dry matter production per hectare.

KEYWORDS: achenes, capitulum; dry matter; green matter; leaves; stem.

\section{INTRODUÇÃO}

O girassol (Helianthus annus L.) vem ocupando espaço de outras culturas pela possibilidade de ser destinado à produção de biodiesel, além de fornecer subprodutos, como torta ou farelo, que podem servir de alternativa para alimentação de ruminantes. Dentre as vantagens da cultura do girassol incluem-se a maior resistência à seca, devido a sua alta capacidade de extrair água do solo, estimada em $92 \%$ contra $64 \%$ do sorgo (BREMMER et al., 1986); resistência ao frio e geadas, devido à ampla adaptabilidade às diferentes condições edafoclimáticas (SOUZA, 1998; LEITE et al., 2005); amplitude da época de plantio no Brasil (julho à fevereiro), permitindo a implantação de outras culturas de verão (produção de grãos e forrageiras) após a sua colheita. Na depressão central do Rio Grande do Sul, o cultivo do girassol é mais recomendado nos meses de julho a setembro, após o cultivo da aveia, que é utilizada no pastejo dos animais e, também, como cobertura vegetal para a cultura subsequente. Após a colheita do girassol, que ocorre de novembro a janeiro, a área pode ser utilizada para a implantação de outras lavouras de grãos, como milho, sorgo e soja ou aproveitada para o plantio de pastagens de verão como o milheto ou sorgo para pastejo, otimizando a produção por área agricultável.

Além dessas vantagens, a planta do girassol ainda pode ser destinada para produção de volumoso, tanto na forma de silagem como de capineira, demonstrando alta qualidade, especialmente pelo maior conteúdo de proteína (TOMICH et al., 2004). A elaboração da silagem de girassol pode ser justificada pela conservação da forragem, fazendo com que haja maior disponibilidade de alimento para os bovinos em momentos em que as adversidades climáticas interferem na disponibilidade de forragem. Segundo DEMARCHI et al. (1995), à medida que a exploração torna-se mais tecnificada, procurando obter melhores índices zootécnicos e maior rentabilidade econômica, os produtores têm adotado sistematicamente a conservação da forragem em silos. A silagem de girassol, como alternativa para a alimentação de ruminantes, vem sendo estudada há alguns anos por pesquisadores (MCGUFFEY \& SCHINGOETHE, 1980; THOMAS et al., 1982; KERCHER et al., 1985), demonstrando potencial nutricional. Entretanto, suas características agronômicas para produção de silagem são pouco conhecidas, já que a maioria dos híbridos pesquisados é destinada à produção de grãos.

Para avaliação das culturas destinadas à produção de silagem é necessário considerar a produção de biomassa e o valor nutritivo da silagem, entre outras características (SOUZA et al., 2003). A participação dos componentes da planta está condicionada ao número de plantas por unidade de área, em função do cultivar utilizado, do estágio de desenvolvimento fenológico, entre outros (MELLO et al., 2006). O girassol possui a característica de produzir alta quantidade de matéria verde e seca, além de bons teores de nitrogênio amoniacal; entretanto, a qualidade em relação aos valores do $\mathrm{pH}$ é considerada mediana (TOMICH et al., 2004).

Por possuir grande diversidade genética, o estudo dos híbridos de girassol mais adequados para cada região é essencial (MELLO et al., 2006), visto que os diferentes cultivares de girassol, implantados na mesma época, podem se comportar de maneira diferenciada quanto à produção e rendimento de seus componentes. Sendo assim, torna-se importante o estudo comparativo das características agronômicas dos cultivares presentes no mercado. Para tanto, o presente trabalho teve como objetivo quantificar a produção e a composição de aquênios, folhas, colmo e capítulo de dois híbridos de girassol (Helianthus annus L.) Helio 251 e Helio 360.

\section{MATERIAL E MÉTODOS}

O experimento foi conduzido no Laboratório de Bovinocultura de Corte da Universidade Federal de Santa Maria (UFSM), localizado na região fisiográfica denominada depressão central, com altitude média de $95 \mathrm{~m}$, latitude de $29^{\circ} 43^{\prime}$ ' Sul e longitude $53^{\circ} 42^{\prime}$ Oeste. Segundo a classificação de Köppen, o clima é "Cfa", subtropical úmido com estiagem no verão, temperatura média mensal máxima de $22^{\circ} \mathrm{C} \mathrm{e}$ mínima variando entre 3 e $18^{\circ} \mathrm{C}$, e precipitação mé- 
dia anual variando de 1300 a $1800 \mathrm{~mm}$. O solo é classificado como Argissolo Vermelho Distrófico Arênico, pertencente à unidade de mapeamento São Pedro (STRECK et al., 2002). A análise de solo foi realizada pelo Departamento de Solos do Centro de Ciências Rurais da UFSM com os seguintes resultados: $\mathrm{pH}=5,8 ; \mathrm{Ca}=7,5 \mathrm{cmol} / \mathrm{dm}^{3} ; \mathrm{Mg}=5,5$ $\mathrm{cmol} / \mathrm{dm}^{3} ; \quad \mathrm{H}+\mathrm{Al}=3,5 \mathrm{cmol} / \mathrm{dm}^{3} ; \quad$ saturação $\%$ : $\mathrm{Al}=0 ;$ base $=77$; índice $\mathrm{SMP}=6.2 ; \quad \% \mathrm{MO}=3,3$ $\%$; argila $=24$; textura $=3, \mathrm{~S}=4,0 \mathrm{mg} / \mathrm{dm}^{3}$; P-Mehlich $=35,8 ; \mathrm{K}=128 \mathrm{mg} / \mathrm{dm}^{3} ; \mathrm{CTCpH} 7=14,8 ; \mathrm{Cu}$ $=1,9 \mathrm{mg} / \mathrm{dm}^{3} ; \mathrm{Zn}=6,2 \mathrm{mg} / \mathrm{dm}^{3} ; \mathrm{B}=0,4 \mathrm{mg} / \mathrm{dm}^{3}$.

Foram utilizados dois híbridos de girassol (Helianthus annus L.): Helio 251 (H251), híbrido simples com aquênios de cor estriada e Helio 360, (H360) híbrido triplo com aquênios de cor estriada preto, implantados em resteva de aveia (Avena strigosa Screb.) dessecada com $200 \mathrm{~L} / \mathrm{ha}$ de calda contendo 3 litros de glifosato $(480 \mathrm{~g} / \mathrm{L})$. As lavouras de girassol foram implantadas em 22 de setembro de 2005 em uma área de seis hectares (ha), subdividida em três ha para cada híbrido. Foram utilizadas cinco sementes/metro linear, com espaçamento entre linhas de $0,8 \mathrm{~m}$. Para adubação de base, utilizaram-se $300 \mathrm{~kg} / \mathrm{ha}$ de adubo na formulação $10-18-20$ de NPK e $0,5 \%$ de boro. Para adubação de cobertura foram utilizados $45 \mathrm{~kg}$ de nitrogênio/ha aplicados 50 dias após o plantio.

A colheita foi realizada 113 dias após a semeadura, quando as plantas do H251 e H360 apresentavam-se em estágio R9, caracterizadas pela maturação fisiológica, com os aquênios maduros, brácteas castanho-amareladas, folhas da base secas, capítulo com o dorso amarelado e com a frente voltada para o solo, mostrando $42,97 \%$ e $39,87 \%$ de matéria seca (MS), respectivamente. A avaliação produtiva da cultura foi realizada através da contagem em 12 pontos de cinco metros lineares/ha de cada híbrido, para determinação do número de plan-

Tabela 1 - Médias e erros-padrão para número e altura de planta, diâmetro do colmo e do capítulo e número de folhas por plantas dos híbridos H251 e H360

\begin{tabular}{lcccc}
\hline Parâmetros & H251 & H360 & Erro-padrão & P>F \\
\hline Número de plantas/m & $3,99^{\mathrm{a}}$ & $3,12^{\mathrm{b}}$ & 1,73 & 0,001 \\
Número de plantas $\mathrm{ha}$ & $49.953,95^{\mathrm{a}}$ & $38.342,10^{\mathrm{b}}$ & 2190,39 & 0,0006 \\
Altura de planta, cm & 141 & 133 & 0,04 & 0,19 \\
Diâmetro de colmo, cm & 6,44 & 6,87 & 0,3 & 0,3189 \\
Diâmetro de capitulo, mm & $174,65^{\mathrm{a}}$ & $138,22^{\mathrm{b}}$ & 11,25 & 0,0281 \\
Número de folhasiplanta & $23,58^{\mathrm{b}}$ & $25,74^{\mathrm{a}}$ & 0,75 & 0,0492 \\
\hline
\end{tabular}

a,b Letras diferentes na mesma linha diferem entre si pelo teste de Tukey em nível de 5\% de significância.

tas por metro linear $(\mathrm{pl} / \mathrm{m})$ e por ha $(\mathrm{pl} / \mathrm{ha})$. Após, coletaram-se cinco amostras, representadas por cinco plantas dos híbridos de girassol, que foram pesadas para determinação do peso da planta em gramas, e medidas individualmente para determinação da altura da planta tomada a cinco $\mathrm{cm}$ do solo até a inserção do capítulo; do diâmetro do colmo a cinco $\mathrm{cm}$ do solo; do diâmetro do capítulo e do número de folhas por planta. A avaliação das variáveis - produção de matéria verde (MV) de aquênios, folhas, colmo, capitulo sem aquênios por ha - foi realizada no momento da colheita, tomando os pesos das partes integrantes da planta para determinação da produção em MV. Posteriormente, as partes de cada planta foram colocadas em estufa de ar forçado a $55^{\circ} \mathrm{C}$ por 72 horas para determinação da produção desses componentes expressos em MS/ha.

$\mathrm{O}$ delineamento experimental foi inteiramente casualizado, composto por dois tratamentos (híbridos de girassol H251 e H360), com 36 repetições (pontos de coleta). Os dados coletados para cada parâmetro foram submetidos à análise de variância e as médias comparadas pelo teste $\mathrm{F}$ em nível de 5\% de significância. Para a realização das análises estatísticas foi utilizado o programa estatístico SAS (1997).

\section{RESULTADOS E DISCUSSÃO}

Na Tabela 1, observa-se que o cultivar H251 apresentou maior população de plantas por metro linear e por hectare $(3,99$ e 49.953) em relação ao cultivar H360 (3,12 e 38.342), demonstrando que o primeiro híbrido apresenta melhor germinação e manutenção de plantas até o momento da colheita do que o segundo, uma vez que o estande/ha introduzido foi de 62.500 plantas/ha para ambos os híbridos.

Ci. Anim. Bras., Goiânia, v.12, n.2, p. 266-273, abr./jun. 2011 
A altura da planta e o diâmetro do caule não diferiram ( $\mathrm{P}>0,05$; Tabela 1$)$ entre os híbridos estudados. $\mathrm{O}$ aumento da altura das plantas, bem como o decréscimo do diâmetro do caule pode ser ocasionado pelo aumento da densidade populacional, gerando maior competição intraespecífica que se estabelece nessa condição, especialmente pela luz incidente (NEPOMUCENO \& SILVA, 1992). A altura da planta já foi correlacionada com índices de produtividade para culturas de sorgo e milho (PIZZARRO, 1978; ZAGO, 1997) e o diâmetro de caule, quando aumentada sua participação, pode diminuir a qualidade do material, principalmente por se tratar de uma estrutura lignificada, interferindo na digestibilidade da fibra. Outros autores também correlacionam essas medidas com fatores relacionados à implantação da cultura, sendo assim, CASTRO et al. (1999) afirmam que o método de incorporação do nitrogênio antes da semeadura também influencia na altura da planta e no diâmetro de colmo. No presente experimento, o nitrogênio foi aplicado da mesma forma aos dois cultivares, podendo ter gerado a similaridade entre a altura das plantas e o diâmetro de caule para os híbridos estudados.

O cultivar H251 apresentou maior diâmetro de capítulo (Tabela 1) que o cultivar H360 (174,65 contra 138,22 mm, respectivamente). A importância do diâmetro do capítulo está relacionada com a quantidade de aquênios produzidos, podendo diferir entre os híbridos presentes no mercado. HECKLER (2002) e TOMICH et al. (2003), avaliando 24 e 13 híbridos de girassol, respectivamente, não constataram diferença $(\mathrm{P}>0,05)$ no diâmetro de capítulo, encontrando valores médios de 162,9 e $173,0 \mathrm{~mm}$, respectivamente. Em relação ao número de folhas, o cultivar H360 apresentou maior quantidade de folhas por planta $(25,74$ contra 23,58 para o cultivar H251). Segundo TOMICH et al. (2003), é desejável que os híbridos de girassol destinadas à produção de silagem apresentem menor participação de caule, que é formado pela altura e diâmetro de caule, e maior participação de capítulo e folha.

Ao se analisar a Tabela 2, observa-se que o cultivar H360 apresentou maior peso de aquênios por planta $(151,09$ contra $60,98 \mathrm{~g}$, respectivamente, para $\mathrm{H} 360$ e H251), mesmo apresentando menor diâmetro de capitulo. Isso se refletiu no melhor preenchimento do capitulo elevando seu peso por planta para este mesmo híbrido (303,79 contra 129,59 g, respectivamente, para $\mathrm{H} 360$ e H251; Tabela 2). O cultivar H360 ainda apresentou maior peso da planta (596,54 g) em relação ao cultivar H251 (281,09 g), o que pode ter sido ocasionado pelo maior peso de aquênios e de colmo (Tabela 2), já que não houve alteração do peso de folhas entre os híbridos testados.

Tabela 2 - Média e erros-padrão para a composição botânica de plantas de híbridos H251 e H360

\begin{tabular}{lcccc}
\hline Parâmetros & H251 & H360 & Erro-padrão & P>F \\
\hline Aquênios, g MV/planta & $60,98^{\mathrm{b}}$ & $151,09^{\mathrm{a}}$ & 20,78 & 0,022 \\
Aquênios, \% MV & $21,66^{\circ}$ & $25,51^{\mathrm{a}}$ & 0,67 & 0,0068 \\
Folhas, g MV/planta & 29,25 & 28,21 & 9,5 & 0,9407 \\
Folhas, \% MV & 10,83 & 4,52 & 2,63 & 0,1408 \\
Colmo, g MV/planta & $61,27^{\mathrm{b}}$ & $120,95^{\mathrm{a}}$ & 13,26 & 0,019 \\
Colmo, \% MV & 22,28 & 20,17 & 1,79 & 0,4364 \\
Capitulo, g MV/planta & $129,59^{\mathrm{b}}$ & $303,79^{\mathrm{a}}$ & 48,2 & 0,0432 \\
Capitulo, \% MV & 45,21 & 49,79 & 3,34 & 0,3697 \\
Plantas, g MV/planta & $281,09^{\mathrm{b}}$ & $596,54^{\mathrm{a}}$ & 86,27 & 0,0415 \\
\hline
\end{tabular}

a,b Letras diferentes na mesma linha diferem entre si pelo teste $\mathrm{F}$ em nível de $5 \%$ de significância.

Quando essas variáveis foram analisadas em relação à matéria seca (MS), notou-se que o cultivar H360 apresentou maior peso de aquênios por planta $(100,12 \mathrm{~g})$ que o cultivar H251 (43,61 g), como pode-se visualizar na Tabela 3, o que levou a uma mai- or participação de capítulos na MS por planta do primeiro $(56,88 \mathrm{~g})$. Devido ao maior peso de aquênios e capítulo por planta, maior estrutura foi necessária para sustentar o capítulo, observando-se maior peso de colmo quando expresso em MS/planta 
(48,58 g; Tabela 3). Pode-se notar maior peso por planta na MS para o cultivar H360 (222,79 g; Tabela 3) em relação ao cultivar H251 (115,08 g; Tabela 3), demonstrando que, dentre as diferenças encontradas para as partes da planta, o peso do capítulo e colmo contribuíram significativamente para o maior peso total da planta $(\mathrm{P}=0,0089)$.

Tabela 3 - Médias e erros-padrão para produção de matéria seca (MS) por planta de aquênios, folhas, colmo e capítulo, e planta, em gramas e percentual, para os híbridos H251 e H360

\begin{tabular}{lcccc}
\hline Parâmetros & H251 & H360 & Erro-padrão & P>F \\
\hline Aquênios, g MS/planta & $43,61^{\mathrm{b}}$ & $100,12^{\mathrm{a}}$ & 11,6 & 0,0137 \\
Aquênios, \% MS & 37,48 & 44,19 & 1,99 & 0,0546 \\
Folhas, g MS/planta & 16,12 & 17,2 & 2,98 & 0,8057 \\
Folhas, \% MS & 14,06 & 7,78 & 1,97 & 0,0647 \\
Colmo, g MS/planta & $29,01^{\mathrm{b}}$ & $48,58^{\mathrm{a}}$ & 3,16 & 0,0047 \\
Colmo, \% MS & 25,45 & 22,79 & 2,49 & 0,4796 \\
Capitulo, g MS/planta & $26,33^{\mathrm{b}}$ & $56,88^{\mathrm{a}}$ & 5,91 & 0,0107 \\
Capitulo, \% MS & 23 & 25,23 & 0,98 & 0,1594 \\
Plantas, g MS & $115,08^{\mathrm{b}}$ & $222,79^{\mathrm{a}}$ & 20 & 0,0089 \\
Plantas, \% MS & 42,97 & 39,87 & 4,34 & 0,63 \\
\hline
\end{tabular}

${ }^{\mathrm{a}, \mathrm{b}}$ Letras diferentes na mesma linha diferem entre si pelo teste $\mathrm{F}$ em nível de $5 \%$ de significância.

As produções em $\mathrm{kg} / \mathrm{ha}$ de aquênio, folhas, caule e capítulo não foram influenciadas pelos híbridos estudados, produzindo em média 4.420; 1.271; 3.705 e $9.061 \mathrm{~kg}$ de $\mathrm{MV} / \mathrm{ha}$, respectivamente (Tabela 4). No entanto, quando expressos em MS/ha, maior produção de aquênios foi observada para o cultivar H360 (3.839,00), o que levou a uma maior produção de matéria seca de capítulos por hectare $(2.180,89)$, como pode ser observado na Tabela 4.
As produções em $\mathrm{kg}$ MS/ha de aquênios e capítulo (Tabela 4) foram superiores ( $\mathrm{P}=0,0461$ e $\mathrm{P}=0,0408$ ) para o H361 (3.839,0 e $2.180,89 \mathrm{~kg} \mathrm{MS} / \mathrm{ha}$, respectivamente) em relação ao $\mathrm{H} 251 \quad(2.178,69 \mathrm{e}$ $1.315,54 \mathrm{~kg} \mathrm{MS} / \mathrm{ha}$, respectivamente). Rendimento médio de 2.066 e $2.053 \mathrm{~kg} \mathrm{MS} / \mathrm{ha}$ de aquênios são relatados por CASTRO et al. (1999) e CARVALHO \& PISSAIA (2002).

Tabela 4 - Médias e erros-padrão para produção de matéria verde (MV) e matéria seca (MS) aquênios, folhas, colmo e capítulo, em kg/ha, para os híbridos Helio 251 e Helio 360

\begin{tabular}{lcccc}
\hline Parâmetros & $\mathrm{H} 251$ & $\mathrm{H} 360$ & Erros-padrão & $\mathrm{P}>\mathrm{F}$ \\
\hline Aquênios, kg/ha MV & 3046,19 & 5793,39 & 845,36 & 0,0613 \\
Aquênios, kg/ha MS & $2.178,69^{\mathrm{b}}$ & $3.839,00^{\circ}$ & 468,33 & 0,0461 \\
Folhas, kg/ha MV & 1461,15 & 1081,53 & 428,28 & 0,5539 \\
Folhas, kg/ha MS & 1030,84 & 659,67 & 155,51 & 0,1424 \\
Colmo, kg/ha MV & 3060,93 & 4350,1 & 507,59 & 0,1226 \\
Colmo, kg/ha MS & 1449,16 & 1862,75 & 137,03 & 0,0768 \\
Capitulo, kg/ha MV & 6473,65 & 11648,04 & 1950,81 & 0,1098 \\
Capitulo, kg/ha MS & $1.315,54^{\mathrm{b}}$ & $2.180,89^{\circ}$ & 235,58 & 0,0408 \\
Produção, kg/ha MV & 14041,94 & 22873,07 & 3522,25 & 0,1266 \\
Produç̧äo, kg/ha MS & 5748,77 & 8542,33 & 826,36 & 0,054 \\
\hline
\end{tabular}

a,b Letras diferentes na mesma linha diferem entre si pelo teste $\mathrm{F}$ em nível de 5\% de significância. 
O rendimento dos aquênios é dependente das condições edafoclimáticas (CARVALHO \& PISSAIA, 2002), como constatado por CASTRO et al. (1999) em anos consecutivos de plantio de girassol em mesma área. Além do tamanho e peso dos aquênios, a concentração de óleo e a visitação de insetos polinizadores podem influenciar no seu rendimento. No presente estudo, as condições climáticas e a polinização dos cultivares foram semelhantes, visto que foram cultivados no mesmo período e foram introduzidas duas caixas/ha de abelhas Apis mellifera para favorecer a polinização das plantas, sendo assim, o fator que mais influenciou o rendimento por ha dos aquênios foi o peso dos mesmos (Tabela 3). HECKLER (2002), estudando 24 híbridos de girassol, constatou que o peso de aquênios foi responsável pelo maior rendimento de aquênios/ha; entretanto, considera que o diâmetro do capítulo seja responsável pelo rendimento de grãos/ha. No entanto, o presente estudo constatou que mesmo que o cultivar H251 tenha apresentado maior diâmetro de capítulo (Tabela 1), apresentou menor rendimento de aquênios/ha (Tabela 4).

Mesmo demonstrando diferenças (Tabela 2) entre os híbridos para o peso das partes da planta, a produção total de matéria verde por hectare foi semelhante ( $\mathrm{P}=1266$; Tabela 4) para os híbridos testados, apresentando média de 18,5 ton. Em relação à produção de matéria seca por hectare, mesmo que o cultivar H360 tenha apresentado menor população de plantas (Tabela1), o maior peso individual das plantas proporcionou maior produção total de matéria seca $(8,5$ contra 5,7 ton de $\mathrm{MS} /$ ha, respectivamente, para $\mathrm{H} 360$ e $\mathrm{H} 251 ; \mathrm{P}<0,10)$. Produções semelhantes ao deste estudo foram encontradas por REZENDE et al. (2002) e TOMICH et al. (2003), sendo que os primeiros encontraram híbridos produzindo 7,21 ton de MS/ha de silagem e os últimos relataram produções de 5,9 ton de MS/ha. Em seu estudo, REZENDE et al. (2003) observaram produ- ções médias de 8,2 e 8,9 ton MS/ha em lavouras com população de plantas de 40 e 60 mil, respectivamente.

A produção das lavouras de girassol também pode ser influenciada pelos problemas com as plantas daninhas, sendo relatadas perdas de $23 \%$ a $70 \%$ no rendimento de grãos, em razão da presença de espécies do tipo monocotiledôneas e dicotiledôneas (VIDAL \& MEROTTO JÚNIOR, 2001). De acordo com os estudos realizados por GIMÉNEZ \& RIOS (1986), a infestação de plantas daninhas foi mais severa até 30 dias após a emergência. A convivência do girassol com plantas daninhas até 21 dias após a emergência (DAE), segundo relatado por BRIGHENTI et al. (2004), não causou efeito sobre o rendimento da cultura. No presente trabalho, houve grande infestação de monocotiledônias, predominantemente o papuã, no intervalo de 21 a 30 DAE, o que pode ter prejudicado a produtividade dos híbridos.

Segundo MCDONALD et al. (1991), o conteúdo relativamente baixo de MS encontrado nas silagens de girassol é considerado fator limitante da cultura, que pode estar relacionado a colheitas precoces e utilização de cultivares que mantêm alta umidade em determinada porção da planta, mesmo em avançados estádios de maturação. Constata-se, na Tabela 5, que os híbridos possuíam teor de MS $(41,42 \%)$ acima do recomendado pela literatura para a ensilagem ( 30 a $35 \%$ ), justificando esse fato em função do monitoramento da MS realizado na lavoura, que deu ênfase ao capítulo que continha considerável presença de água na sua constituição, enquanto os aquênios e principalmente as folhas apresentavam alta concentração de MS. De acordo com VAN SOEST (1994), a obtenção de silagem com teores entre 30 e $35 \%$ favorece o desenvolvimento de fermentações láticas, consideradas ideais no processo de ensilagem.

Tabela 5 - Médias e erros-padrão para teor de matéria seca (\% MS) de aquênios, folhas, colmo e capitulo dos híbridos Helio 251 e Helio 360

\begin{tabular}{lcccc}
\hline Parâmetro & H251 & H360 & Erro-padrão & P>F \\
\hline Aquênios, \% MS & 73,81 & 67,66 & 3,51 & 0,262 \\
Folhas, \% MS & 66,64 & 75,01 & 13,38 & 0,6738 \\
Colmo, \% MS & 47,43 & 45,49 & 5,33 & 0,8056 \\
Capitulo, \% MS & 22,65 & 20,33 & 3,32 & 0,6379 \\
Planta, \% MS & 42,97 & 39,87 & 4,34 & 0,63 \\
\hline
\end{tabular}


A ensilagem de plantas com teores abaixo de $30 \%$ de MS pode provocar perdas por lixiviação de até $8 \%$ de nutrientes, além de favorecer a fermentação acética e butírica; no entanto, a ensilagem com teores acima de $35 \%$ dificulta a compactação do material ensilado, permitindo respiração intensa da forragem picada, levando à ocorrência de fermentação alcoólica ou glicídica (CONSENTINO, 1978). De acordo com KUNG \& SHAVER (2001), para que o processo fermentativo seja comprometido e os valores de $\mathrm{pH}$ estejam elevados é necessário que a MS seja superior a 50\%.

\section{CONCLUSÃO}

O híbrido Hélio 251 apresentou maior quantidade de plantas/ha, mas essas apresentaram menor participação de aquênios, colmo e capítulo em relação ao híbrido Hélio 360.

O híbrido Hélio 360 mostrou superioridade na produção de matéria seca por hectare mostrando ser mais adequado para ensilagem que o híbrido Hélio 251.

\section{REFERÊNCIAS}

BREMMER, P.M.; PRESTON, G.K.; GROTH, C.F. A field comparison of sunflower (Helianthus annus) and Sorghum (Sorghum bicolor) in along drying cycle. I. Water extration. Australian Journal of Agricultural Research, Cairo, v.37, n.5, p.483-493, 1986.

BRIGHENTI, A.M.; CASTRO, C.; MENEZES, C.C.; OLIVEIRA, F.A.; FERNANDES, P.B. Aplicação simultânea de dessecantes e boro no manejo de plantas daninhas e na nutrição mineral das culturas de soja e girassol. Planta Daninha, Viçosa, v.24, n.4, p.797-804, 2006.

CARVALHO, D.B.; PISSAIA, A. Cobertura nitrogenada em girassol sob plantio direto na palha: I - Rendimentos de grãos e seus componentes, índice de colheita e teor de óleo. Scientia Agrícola, Piracicaba, v.3, n.1-2, p.41-45, 2002.

CASTRO, C. DE; BALLA, A.; CASTIGLIONI, V.B.R.; SFREDO, G.J. Doses e métodos de aplicação de nitrogênio em girassol. Scientia Agrícola, Piracicaba, v.56, n.4, p.827-833, 1999.

CONSENTINO, J.R. Fermentações da silagem. Zootecnia, v.16, n.1, p.57-61, 1978.

DEMARCHI, J.J.A.A.; BOIN, C.; BRAUN, G. A cultura do sorgo (Sorghum bicolor L. Moench) para produção de silagens de alta qualidade. Revista Brasileira de Zootecnia, Viçosa, v.33, n.3, p.111-136, 1995.

GIMENEZ, A.; RIOS, A. Control de malezas. In: CEN-
TRO DE INVESTIGACIONES AGRÍCOLAS ALBERTO BOERGER. Girasol: algunos aspectos de manejo y producción. Uruguai: Estación Agropecuária La Estanzuela, p.15-22, 1986.

HECKLER, J.C. Sorgo e girassol no outono-inverno, em sistemas plantio direto, no Mato Grosso do Sul, Brasil. Ciência Rural, Santa Maria, v.32, n.3, p.517-520, 2002.

KERCHER, C.J.; SMITH, W.L. AND JACKSON, G. Type of silages and chopped or baled alfalfa hay and silages for wintering beef calves. Journal of Animal Science, v.61, p.327, 1985.

KUNG, L. AND SHAVER, R. Interpretation and use of silage fermentation analysis reports: In: FOCUS ON FORAGE, 2001, Wisconsin. Disponível em: $<$ http://www.uwex.edu/ces/crops/uwforage/Fermentation.pdf $>$. Acesso em: 17/07/2009.

LEITE, R.M.V.B. DE C.; BRIGHENTI, A.M.; CASTRO, C. DE. Girassol no Brasil. Londrina: Embrapa Soja, 2005. 641p.

MCDONALD, P.; HENDERSON, A.R. AND HERON, S. The Biochemistry of Silage. 2nd edition. Marlow: Chalcombe Publications, 1991.340p.

MCGUFFEY, R.K. AND SCHINGOETHE, D.J. Feeding values of a high oil variety of sunflowers as silage to lactating dairy cows. Journal of Animal Science, v.63, p.1109-1113, 1980.

MELLO, R.; NÖRMBERG, J.L.; RESTLE, J. NEUMANN, M.; QUEIROZ, A. C. DE; COSTA, P. B.; MAGALHÃES, A. L. R.; DAVID, D. B.Características fenológicas, produtivas e qualitativas de híbridos de girassol em diferentes épocas de semeadura para a produção de silagem. Revista Brasileira de Zootecnia,Viçosa, v.35, n.3, p.672-682, 2006.

NEPOMUNCENO, A.L. AND SILVA, P.R.F. Efeito do arranjo de plantas e da presença de ervas daninhas nas características de plantas associadas à colheita de girassol. Pesquisa Agropecuária Brasileira, Brasília, v.27, p.1057-1063, 1992.

PIZARRO, E.A. Conservação de forragens. I. Silagem. Informe Agropecuário, Belo Horizonte, v.4, n.47, p.2028, 1978.

REZENDE, A.V.; EVANGELISTA, A.R.; SIQUEIRA, G.R.; SANTOS, R.V; SALES, E.C.J.; BERNARDES, T.F. Avaliação do potencial do girassol (Helianthus annus L.) como planta forrageira para ensilagem na safrinha, em diferentes épocas de cortes. Ciência e Agrotecnologia, Lavras, v.26, p.1548-1553, 2002.

REZENDE, A.V.; EVANGELISTA, A.R.; SIQUEIRA, G.R.; BARCELOS, A.F.; ROCHA, G.P.; SANTOS, R.V. Efeito da densidade de semeadura sobre a produtividade e composição bromatológica de silagens de girassol (Helianthus annus L.). Ciência Agrotecnologia, dez., p.1672-1678, 2003. 
SOUZA, D.B. Girassol: uma nova opção para silagem. Gado Holandês, São Paulo, n.472, p.6-10, abril, 1998.

SOUZA, G.V.; PEREIRA, O.G., MORAES, S.A. Valor nutritivo das silagens de sorgo. Revista Brasileira de Zootecnia, v.32, n.3, p.753-759, 2003.

STATISTICAL ANALYSES SYSTEM - SAS. User's guide statistics. 4.ed. Cary. 2, 1997. p.943.

STRECK, E.D.; KÄMPF, N.; DALMOLIN, R.S.D. Solos do Rio Grande do Sul. Porto Alegre: EMATER/RS, 2002. 126p.

THOMAS, V.M.; SNEDDON, D.N.; ROFFLER, R.E; MURRAY, G.A. Digestibility and feeding value of sunflower silage for beef steers. Journal of Animal Science, Philadelphia, v.54, p.933-937, 1982.

TOMICH, T.R.; GONÇALVES, L.C.; TOMICH, R.G.P. et al. Características químicas e digestibilidade in vitro de silagens de girassol. Revista Brasileira de Zootecnia, v.33, n.6, p.1672-1682, 2004.

TOMICH, T.R.; RODRIGUES, J.A.S.; GONÇALVES, L.C.; TOMICH, R.G.P.; CARVALHO, A.U. Forage potencial of sunflower cultivars produced in doublé-cropping system for silage. Arquivos Brasileiros de Medicina Veterinária e Zootecnia, Belo Horizonte, v.55, n.6, p.756-762, 2003.

VAN SOEST, P.J. Nutritional ecology of the ruminant. 2.ed., Ithaca: Comstock,1994. 476p.

VIDAL, R. A.; MEROTTO JR, A. Herbicidologia. Porto Alegre:Evangraf, 2001. 152p.

ZAGO, C.P. Utilização do sorgo na alimentação de ruminantes. In: MANEJO CULTURAL DO SORGO PARA FORRAGEM, Circular técnica, 17, Sete Lagoas:Embrapa-CNPMS, 1997. p.9-26. Disponível em: http://livraria.sct.embrapa.br/liv_resmos/pdf/00072670.pdf. Acesso em: 17/07/2009 